\title{
Analysis of temporal changes in the expression of estrogen-regulated genes in the uterus
}

\author{
H Watanabe ${ }^{1,2}$, A Suzuki $^{1,2}$, M Kobayashi $^{1,2}$, E Takahashi $^{1,2}$, M Itamoto ${ }^{1,2}$, \\ D B Lubahn ${ }^{3}$, H Handa ${ }^{4}$ and T Iguchi ${ }^{1,2}$ \\ ${ }^{1}$ Center for Integrative Bioscience, Okazaki National Research Institutes, 5-1 Higashiyama, Myodaiji, Okazaki, Aichi 444-8585, Japan \\ ${ }^{2}$ Core Research for Evolutional Science and Technology, Okazaki National Research Institutes, 5-1 Higashiyama, Myodaiji, Okazaki, \\ Aichi 444-8585, Japan \\ ${ }^{3}$ Department of Molecular Biology, University of Missouri, Columbia, Missouri 65211, USA \\ ${ }^{4}$ Frontier Collaborative Research Center, Tokyo Institute of Technology, 4259 Nagatsuta-cho, Yokohama, Kanagawa 226-8503, Japan
}

(Requests for offprints should be addressed to T Iguchi, Center for Integrative Bioscience and Core Research for Evolutional Science and Technology, Okazaki National Research Institutes, 5-1 Higashiyama, Myodaiji, Okazaki, Aichi 444-8585, Japan; Email: taisen@ nibb.ac.jp)

\begin{abstract}
In order to understand early events caused by estrogen in vivo, temporal uterine gene expression profiles at early stages were examined using DNA microarray analysis. Ovariectomized mice were exposed to $17 \beta$-estradiol and the temporal mRNA expression changes of ten thousand various genes were analyzed. Clustering analysis revealed that there are at least two phases of gene activation during the period up to six hours. One involved immediate-early genes, which included certain transcription factors and growth factors as well as oncogenes. The other involved early-late genes, which included genes related to RNA and protein synthesis. In clusters of down-regulated genes, transcription factors, proteases, apoptosis and cell cycle genes were found. These hormone-inducible genes were not induced in estrogen receptor (ER) $\alpha$ knockout mice. Although expression of ER $\beta$ is known in the uterus, these findings indicate the importance of $E R \alpha$ in the changes in gene expression in the uterus.
\end{abstract}

Journal of Molecular Endocrinology (2003) 30, 347-358

\section{Introduction}

The sex hormone, 17ß-estradiol (E2), is a well-characterized steroid hormone that controls the development of the reproductive tract and mammary gland, regulates the estrous cycle, controls lactation, and exerts regulatory influences that are important for bone, liver and cardiovascular systems, as well as for behavior. These effects are mainly exerted by estrogen receptors (ERs) (Couse \& Korach 1999). The critical regulatory functions of estrogen are mediated by ERs and their molecular mechanisms of transactivation have been well characterized. At least two types of estrogen receptors, $\mathrm{ER} \alpha$ and $\mathrm{ER} \beta$, are known in mammals (Green et al. 1986, Kuiper et al. 1996). They bind to estrogen-response elements (EREs) within enhancer regions of target genes to regulate transcription in a ligand-dependent manner. The bound ERs then recruit cofactors related to p160 family members such as SRG-1 (Onate et al. 1995), GRIP1 and amplified in breast cancer 1 (AIB1) (Anzick et al. 1997), and histone acetylases such as CBP and p300 (Chakravarti et al. 1996) to reorganize chromatin structure and activate transcription.

Despite great progress in characterizing the molecular biology of ERs, the mechanisms underlying the physiological changes such as the uterotropic effect induced by E2 remain largely unknown. This is partly because most of the genes known to be activated by estrogen have been determined by studying the effects of E2 on cultured cells and because our knowledge about the genes actually activated in vivo is rather limited. Especially, our knowledge of temporal changes of estrogen response genes in the rodent uterus is not sufficient to allow a full understanding of the long-term physiological effects of estrogen. For example, c-fos and c-jun are known to be activated 
within 30 min-2 h (Weisz \& Bresciani 1988, Weisz et al. 1990) and c-myc is activated for $4-6 \mathrm{~h}$ after estrogen administration. On the other hand, expression of estrogen-responsive zinc finger protein is at its maximum around $10 \mathrm{~h}$ (Inoue et al. 1993) and lactoferrin and complement C3 (Sundstrom et al. 1989) are known to be activated after 24-78 h (Pentecost \& Teng 1987). Although these genes are known as estrogen responsive genes, the mechanisms relating to the temporal control of the expression of these genes is largely unknown. Thus, determining the temporal changes of gene expression levels affected by estrogen and the identification of these genes are important for our understanding of the transcriptional cascade evoked by estrogen.

The uterus is a prominent E2 target organ, which also shows drastic changes during the estrous cycle. In order to clarify the mechanisms of the effect of estrogen on the reproductive tract, it is essential to identify the genes affected by estrogen, especially those whose expression is affected during the early stages of the uterine response. However, our knowledge of the overall number of uterine genes regulated by estrogen is rather limited except for information from microarray analysis (Watanabe et al. 2002), and only a limited number of genes, such as proto-oncogenes (Weisz \& Bresciani 1988, Weisz et al. 1990) and growth factors (Liu et al. 1987, Murphy et al. 1987, Huet-Hudson et al. 1990), are known to be early induced genes, which are also activated by other stimuli such as mitogen and serum in vitro. As the ER is one of the transcription factors, an analysis of changes in mRNA expression patterns caused by E2 provides a powerful tool for understanding the molecular mechanisms underlying estrogen action. Thus, genome-wide gene expression profiling by E2 administration is important to fully understand the dramatic effects of estrogen on the uterus.

To analyze genome-wide gene expression changes, we employed the DNA microarray technique. DNA microarray technology has recently been developed and successfully applied to the genome-wide analysis of gene expression as influenced by various stimuli such as serum (Iyer et al. 1999), hormones (Feng et al. 2000) or chemicals (Marton et al. 1998). High-density oligonucleotide arrays (Lockhart et al. 1996) are especially suitable for genome-wide mapping of gene expression because a large number of genes can be analyzed at one time and it is readily scalable to the simultaneous monitoring of tens of thousands of genes.

In this study, the early time course changes in the expression of ten thousand genes were profiled and E2-regulated genes were clustered. We found that there are at least two phases in the gene activation pattern. As the change in gene expression was not evoked in the ER $\alpha$-deficient mice, a major contribution of $\mathrm{ER} \alpha$ but not $\mathrm{ER} \beta$ in the transcription regulation in the uterus was indicated.

\section{Materials and methods}

\section{Animals}

Animals were housed under a 12-h light, 12-h darkness cycle. ER $\alpha$ knockout ( $\alpha$ ERKO) mice and their wild-type counterparts (C57/BL6/J background; Lubahn et al. 1993) were ovariectomized at eight weeks of age. After two weeks, the ovariectomized mice were injected with $17 \beta$ estradiol (E2; Sigma; $5 \mu \mathrm{g} / \mathrm{kg}$ body weight (b.w.)) intraperitoneally and total uterine RNA was prepared. Total uterine RNA from wild-type mice was prepared at $0 \mathrm{~h}, 1 \mathrm{~h}, 2 \mathrm{~h}, 6 \mathrm{~h}, 12 \mathrm{~h}, 24 \mathrm{~h}$ and $48 \mathrm{~h}$ after estrogen administration $(5 \mu \mathrm{g} / \mathrm{kg}$ b.w.). Total uterine RNA from $\alpha$ ERKO mice was prepared $6 \mathrm{~h}$ after E2 administration and processed as for the wild-type. All animal experiments were approved by the institutional animal committee.

\section{Preparation of labeled cRNA and hybridization}

Total uterine RNA was extracted using TRIZOL (Invitrogen, Tokyo, Japan) and purified using RNeasy (Qiagen, Tokyo, Japan). Total RNA was converted into double stranded cDNA using the SuperScript Choice System (Invitrogen) and labeled cRNA was synthesized according to the manufacturer's protocol (Amersham Biosciences, Tokyo, Japan). Labeled cRNA was purified using RNeasy, denatured and subjected to limited fragmentation in fragmentation buffer $(40 \mathrm{mM}$ Tris-HCl (pH 8.1), $100 \mathrm{mM}$ potassium acetate, $30 \mathrm{mM}$ magnesium acetate) by heating at $94^{\circ} \mathrm{C}$ for 35 min. Fragmented cRNA was mixed with hybridization buffer containing $100 \mathrm{mM} 2-(\mathcal{N}-$ Morpholino) ethane sulfonic acid, $1 \mathrm{M} \mathrm{NaCl}$, $20 \mathrm{mM}$ EDTA and $0 \cdot 01 \%$ Tween 20 and control oligonucleotides. High-density oligonucleotide 
arrays (Mouse U74 A, Affymetrix, Amersham Biosciences) were hybridized for $16 \mathrm{~h}$ at $45^{\circ} \mathrm{C}$. Arrays were then washed, stained with streptavidinphycoerythrein (Molecular Probes, Funakoshi, Tokyo, Japan) in an Affymetrix fluidix station and scanned with an argon-ion laser confocal scanner (Amersham Biosciences).

\section{Data analysis}

Scanned data were analyzed with GeneChip software (Affymetrix, Amersham Biosciences) and detailed methods for data analysis have already been described (Lockhart et al. 1996). Briefly, each gene is represented by the use of 20 perfectly matched (PM) and mismatched (MM) control oligonucleotides. The MM probes are used to detect background levels and cross-hybridization signals. The decision about the absence or presence of an mRNA is made by GeneChip software using values derived from these 20 sets of probes (Lockhart et al. 1996). To determine the quantitative RNA abundance, the average of the differences (called 'average difference') representing PM minus MM for each genespecific probe is calculated. To normalize data, genes called 'A' (absence) during the $6 \mathrm{~h}$ were masked, negative average differences were adjusted to zero and rescaling factors were adjusted to produce an average intensity that equalled 2500.

To obtain convincing gene expression levels from the DNA microarray, we repeated the same experiment at least two times independently and the differences in intensities were calculated. In order to maintain reproducibility, we only selected the genes whose expression level changes were less than twofold between two independent experiments under the same conditions and average values were used as gene expression levels.

\section{Clustering analysis}

Clustering analysis was performed using Gene Cluster software based on a self-organizing maps algorithm (Tamayo et al. 1999). Genes showing a $\mathrm{max} / \mathrm{min}$ ratio greater than threefold in their gene expression levels were selected and their expression levels, represented by the average difference were normalized to a mean value of zero and a variance of one. The normalized data were then clustered using GeneCluster (http://www-genome.wi.mit. edu/cancer/software/software.html).

\section{Quantitative real time-PCR (Q-RT-PCR)}

Total RNA was extracted from the uterus using TRIZOL and purified with RNeasy. cDNA was synthesized from purified total RNA by Superscript II $\mathrm{RT}(-)$ (Invitrogen) with random primers at $42{ }^{\circ} \mathrm{C}$ for $60 \mathrm{~min}$. PCR reactions were performed in the PE Prism 5700 sequence detector (PE Biosystems, Tokyo, Japan) using SYBR-Green (Molecular Probes, Eugene, OR, USA) in the presence of appropriate primers according to the manufacturer's instructions. The assay uses fluorescence emitted by SYBR-Green to quantify double-stranded DNA produced during the PCR reaction. The use of a sequence detector allows the continuous measurement of fluorescent spectra of all 96 wells of the thermal-cycler during PCR amplification. The model 5700 software constructs amplification plots from extension phase fluorescent emission data collected during PCR amplification. $\mathrm{C} \tau$ (threshold) values were calculated by determining the point at which fluorescence exceeds a threshold limit (usually 10 times the S.D. of the baseline).

For the standard curves of the genes, serial dilutions of a known amount of a cDNA sample were used. The $\mathrm{C} \tau$ values of each gene were plotted on these standard curves to obtain the number of copies present in the initial cDNA sample. Each PCR amplification was performed in triplicate, using the following conditions: $2 \mathrm{~min}$ at $50{ }^{\circ} \mathrm{C}$ and $10 \mathrm{~min}$ at $95^{\circ} \mathrm{C}$, followed by a total of 40 two-temperature cycles $\left(15 \mathrm{~s}\right.$ at $95^{\circ} \mathrm{C}$ and $1 \mathrm{~min}$ at $60{ }^{\circ} \mathrm{G}$ ). Gene expression levels were normalized to that of $28 \mathrm{~S}$ ribosomal RNA. Gel electrophoresis and melting curve analyses were performed to confirm correct amplicon size and absence of nonspecific bands.

Primers were chosen with the assistance of the Primer Express (PE) computer program, and were NM_010234 (c-fos): ACGCACAGACCA CACAACAGA, GCTAGCAGCGACAGCTCG TG; U83902 (Mad2): GCGGTCTGGGGTGA GG, TGGGGCGAGCTGCTGT; U19118 (LRG21, ATF3): GGGTCGTA TGCAAAGCAG GAT, TCAAGGTAGACACTTGTGGGTGAA; U77630 (adrenomedullin): ATAAGCGTCATTA GTACTTGAACT, TTGGACGTTCGTCGGTA GGT; M28845 (EGR-1): GAGTACGCGTTCGT GCGTAAAA, GGTAAGGACTGAGGGTGAAA AACA; NM_010849 (Myc): AGGGTTCGTTCT 

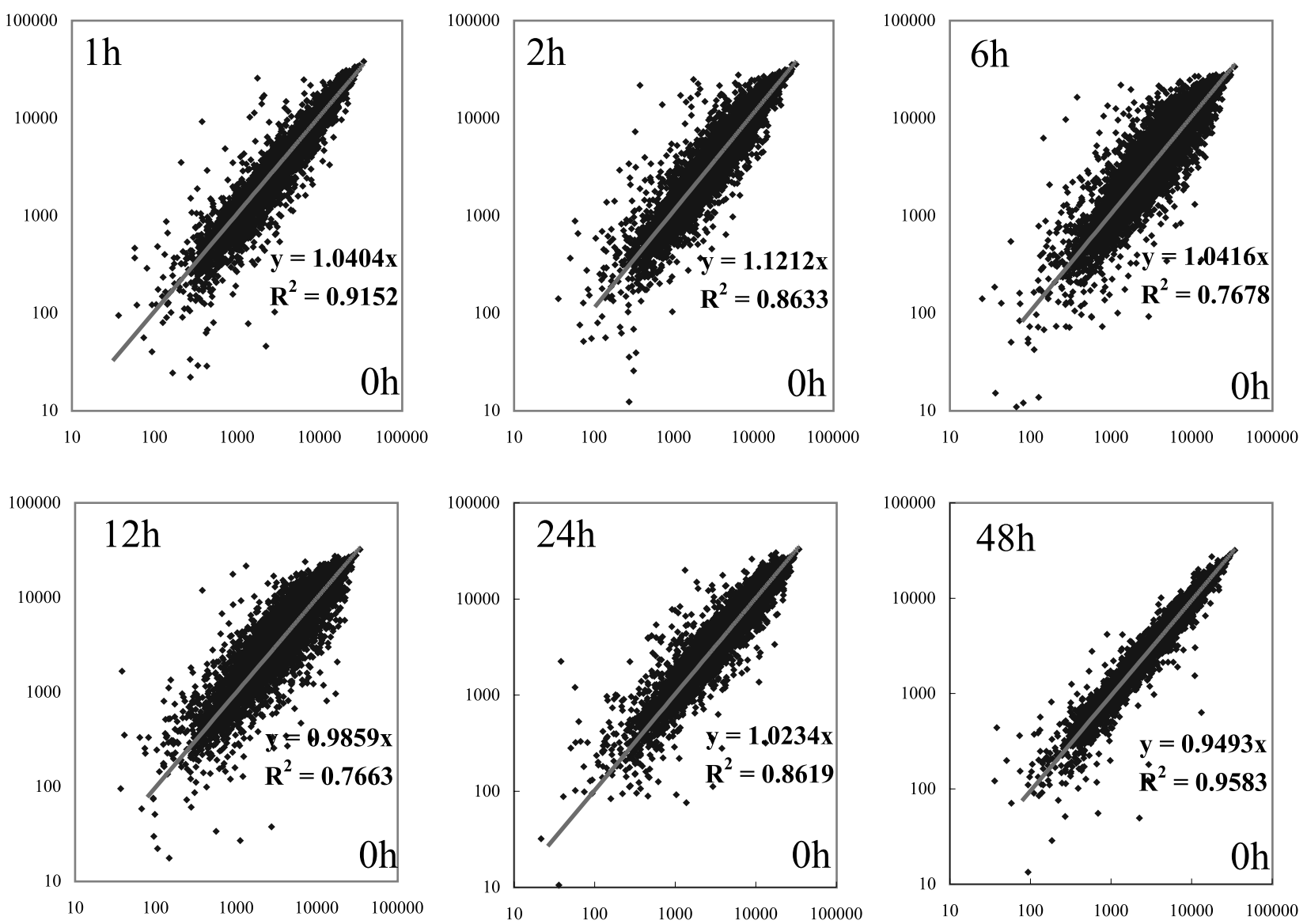

Figure 1 Temporal changes of gene expression pattern. Scatter plot of gene expression levels between each time point ( $\mathrm{Y}$ axis) and $\mathrm{O} \mathrm{h}$ ( $\mathrm{X}$ axis). Each dot corresponds with each gene, whose $\mathrm{X}$ value and $\mathrm{Y}$ value indicate the gene expression level represented by average difference at $\mathrm{O}$ h and at the indicated time point respectively. Correlation coefficients and formula used for the derivation of the correlation curve are also indicated.

GACAGAACTGA， GGTTAGGCTTTGGGAT GCAT; AF009246 (DEXRAS1): GGAAGTAGA GCAGGGGGAGA， CGAAGTAGGGACAAGG CTGA; L07264 (HB-EGF): TGGAGAATCGC CTATACACA, CAGGACGACAGGCAAGACT; M96163 (serum inducible kinase): ACGAGAC GAGGCTAAGGTGTAGAG, GACAGGTATCT CAGGGAAAACTGC; M59821 (pip92): TTG AATGTCAGGGTGGAACTCT, ATGGTAGT GAAACGGCCTTGA; NM_146217 (alanyl-tRNA synthetase): TTGACAGCAACGCGAACGA, CT CGACTCTCGATCTCGAGGAT; XM_133968 (cysteinyl-tRNA synthetase): GGGCGACTTGAC GATAGGA, AAGTTTTTGAGTGACTTGGAC ATCT; XM_123283 (histidyl tRNA synthetase): ATTTTGACATTGCGGGACAGT, GGCACTC TGGATCAGGAATCA; AF123263 (phenylalanyl tRNA synthetase beta subunit): GGAGGACG
CAGGTATTGGTTAT, GTAGGTTTTGGGGA GAGTCATCT; BC008612 (seryl-aminoacyltRNA synthetase 1): CGCAGAGAACGTGCT GAATTTC, TGAGACTTTCAGGGGAGCTA GC; U95826 (cyclin G2): ACTGCGGAGTT GTCTTCTCGAA， GCACAGAGCTAATACA GATGGTCTT; U42467 (leptin receptor): CTTT GGAAGCCCCTGACGAA, GGTACGTCGTCA CACTACACAGT; M61215 (ferrochelatase) TG GTGAAGCTGCTGGATGAG, GGGATGGAC GTACGGGAATC; Y13090 (caspase 12): ATT GGCCCATGAATCACATCTAAT, GGACAAA GCTTCAGTGTATCTTGGA; AJ007970 (guanylate nucleotide binding protein 2): CAGCGACGT GTGTTATAGGTACT, ACGTATGGCTGGG CATGATGAA; X00525 (28S): AGACGGTGGT GAGACAGGTTAGTT， GGAGGATTACGAT GGCAACAA. 

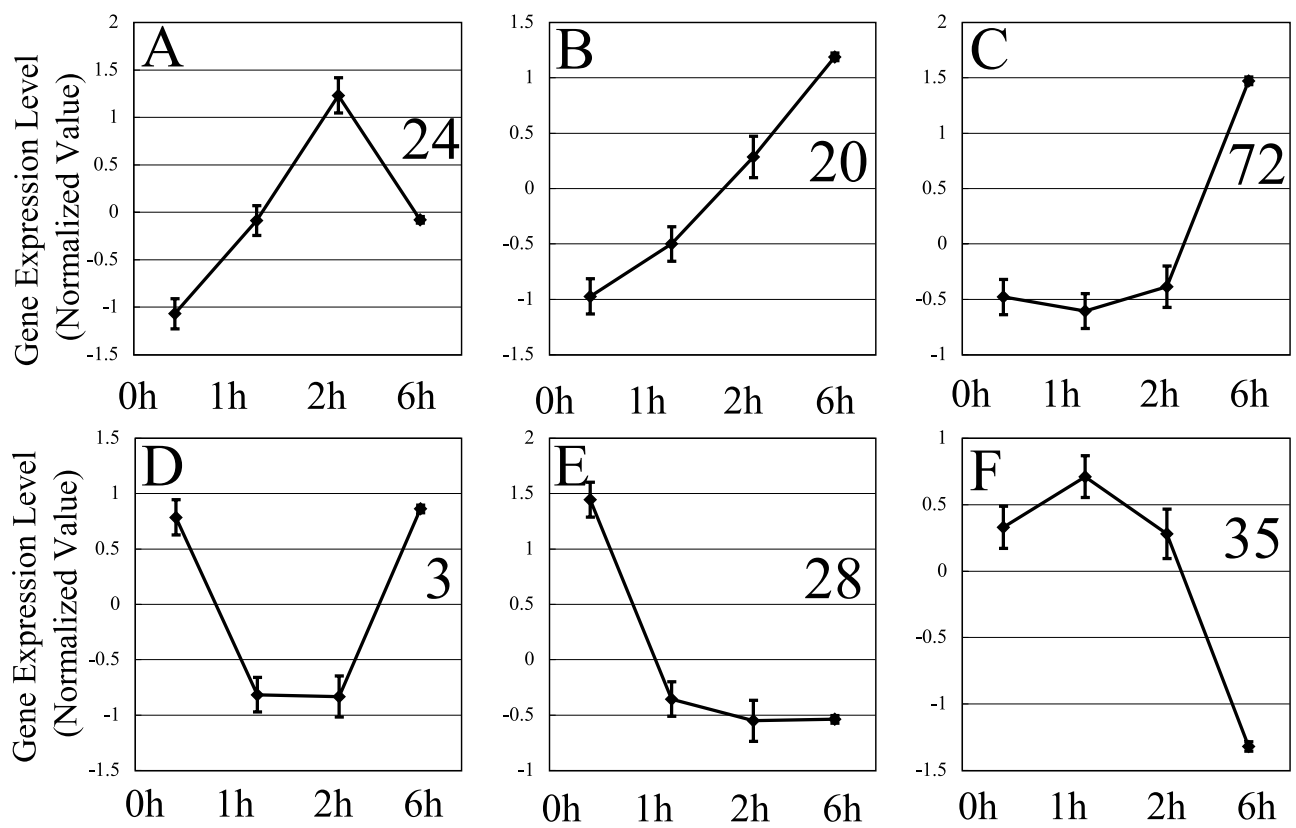

Figure 2 Clustering of gene expression patterns. The 182 genes that passed the variation filter were normalized to obtain a mean $=0$ and a s.D. $=1$ across time points. After the normalization, they were grouped into six clusters using a self-organizing map (GeneCluster (Tamayo et al. 1999)). Each resultant clustering pattern is indicated in separate panels (A-F). Clustering patterns of the activated genes are indicated in panels A-C and repressed genes are indicated in panels D-F. Each cluster is represented by the centroid of normalized values on the $\mathrm{Y}$-axis and time points on the $\mathrm{X}$-axis. These six patterns indicate the representative temporal gene expression changes of the selected genes. Error bars indicate the S.D. of the average expression levels. Note that the normalized values have negative values.

\section{Results}

In order to get an overview of the temporal expression of genes affected by estrogen in the uterus, total uterine RNA was prepared at $1 \mathrm{~h}, 2 \mathrm{~h}$, $6 \mathrm{~h}, 12 \mathrm{~h}, 24 \mathrm{~h}$ and $48 \mathrm{~h}$ after estrogen administration. To evaluate temporal changes in gene expression, we compared gene expression levels at each time point with $0 \mathrm{~h}$. As shown in Fig. 1, the changes in gene expression reached a maximum between 6 and $12 \mathrm{~h}$ after estrogen administration. After $12 \mathrm{~h}$, the number of estrogen-affected genes decreased and no obvious changes remained at $48 \mathrm{~h}$. This result indicates that a single dose of estrogen, $5 \mu \mathrm{g} / \mathrm{kg}$ b.w., which is sufficient to provoke a uterotropic effect by repetitive administration, can affect uterine gene expression up to 12-24 h after administration. Thus, we used this dose of estrogen to study early gene expression during the period up to $6 \mathrm{~h}$ after estrogen administration.

\section{Clustering of changes in gene expression}

In order to examine the temporally regulated genes, we selected the genes whose expression levels were changed more than threefold during $6 \mathrm{~h}$ and their temporal gene expression patterns were clustered. When the clustering analysis based on the self-organizing map algorithm (Tamayo et al. 1999) was applied to the filtered genes induced during the period up to $6 \mathrm{~h}$, temporal changes in estrogen-affected gene expression could be clustered into six groups. This result indicates that temporal changes of estrogen response genes show at least six gene expression patterns up to $6 \mathrm{~h}$. Figure 2 shows the centroids in the clustered pattern when six $(3 \times 2)$ nodes were used for the clustering analysis. The number of genes in each cluster is also indicated in Fig. 2. By clustering analysis, three clusters of induced genes (clusters A-C) and three clusters of repressed genes (clusters D-F) were revealed. 


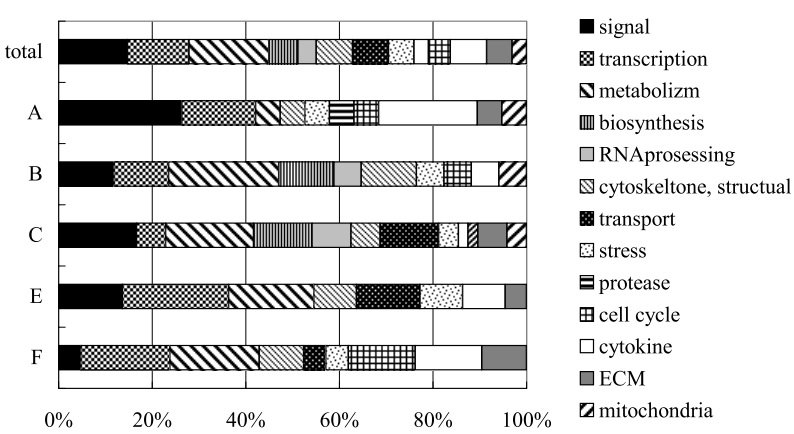

Figure 3 Functional classification of clustered genes. Gene functions of the clustered genes were categorized into thirteen functions (right panel) and the percentage representation of each function is indicated. Each cluster corresponding to Fig. 2 is indicated on the left. Cluster D was omitted because it contained only three genes. EST genes were also categorized based on gene similarity. ECM, extra cellular matrix.

In the case of induced genes, at least three groups of gene expression patterns were revealed (A-C). The genes in the first group (immediateearly genes, cluster A) were activated within a few hours of estrogen administration and their induction was transient. The second group of genes were induced in a linear fashion (cluster B). Genes in the third group (early-late induced genes, cluster C) were activated during the decline in the expression of the early genes.

Among the clusters of repressed genes (D-F), cluster D was characteristic because only three genes were selected in this cluster. On the other hand, the number of gradually repressed genes or genes repressed at the early-late stage (clusters $\mathrm{E}$ and $\mathrm{F}$ respectively) were comparable to the number of induced genes (clusters B and $\mathrm{C}$ respectively). In contrast to the limited number of genes known to be repressed by E2, our findings show that a relatively large number of genes are repressed by E2. The list of clustered genes is indicated in Fig. 4.

\section{Functions of the genes in each cluster}

Based on the clustering result, we examined the functions of the genes and the percentage representation of each gene function in each cluster. When gene functions were categorized into 13 groups (names of the categories are indicated in Fig. 3), it was found that the dominant gene functions were different in each cluster (Fig. 3). In cluster A, there was a notable occurrence of a large number of immediate early genes together with a limited number of known genes, such as heparinbinding epidermal growth factor (Wang et al. 1994). Their expression patterns and names are indicated in Fig. 5 (upper panel). In cluster C (early-late genes), genes related to RNA processing, such as capping, poly-adenylation and splicing were activated and genes responsible for protein synthesis such as initiation factors, elongation factors, releasing factors and tRNA-synthetases were found. Most of the genes related to RNA and protein synthesis that were analyzed by the array showed similar temporal changes, which are indicated in Fig. 5 (lower panel). This result indicates that a part of functionally related genes are regulated in a similar fashion at the transcriptional level.

The expressions patterns of some of the genes were further confirmed by Q-RT-PGR as shown in Fig. 6. Although temporal changes in gene expression patterns as determined by the two systems were not completely identical, most of the expression patterns determined by DNA microarray analysis agreed well with those determined by Q-RT-PCR. As shown in Fig. 6, temporal changes of gene expression were confirmed not only for induced genes but also for repressed genes.

\section{Effect of estrogen in a $\alpha$ ERKO mouse}

In order to determine if these genes are affected by $\mathrm{E} 2$ in an ER $\alpha$-dependent manner, we examined gene expression changes induced by $\mathrm{E} 2$ in $\alpha \mathrm{ERKO}$ mice. The fold changes of wild-type mice were calculated and compared with those of ERKO mice and indicated by scatter plot (Fig. 7). Most genes affected by $\mathrm{E} 2$ in wild-type mice (X-axis) were not affected in $\alpha$ ERKO mice (Y-axis), indicating that E2 does not affect E2-mediated gene expression in mice lacking the $\mathrm{ER} \alpha$ receptor. This result indicates that uterine gene expression changes induced by estrogen are mainly mediated by $\operatorname{ER} \alpha$ at the transcriptional level. The fact that neither induced genes nor repressed genes were affected by $\mathrm{E} 2$ in $\alpha \mathrm{ERKO}$ mice suggests that $\mathrm{ER} \alpha$ also regulates most of the estrogen-repressed genes. Our results are consistent with previous observations in $\alpha$ ERKO mice showing that $\alpha \mathrm{ER}$ disruption causes severe uterine defects (Lubahn et al. 1993) 
Up Regulated Genes

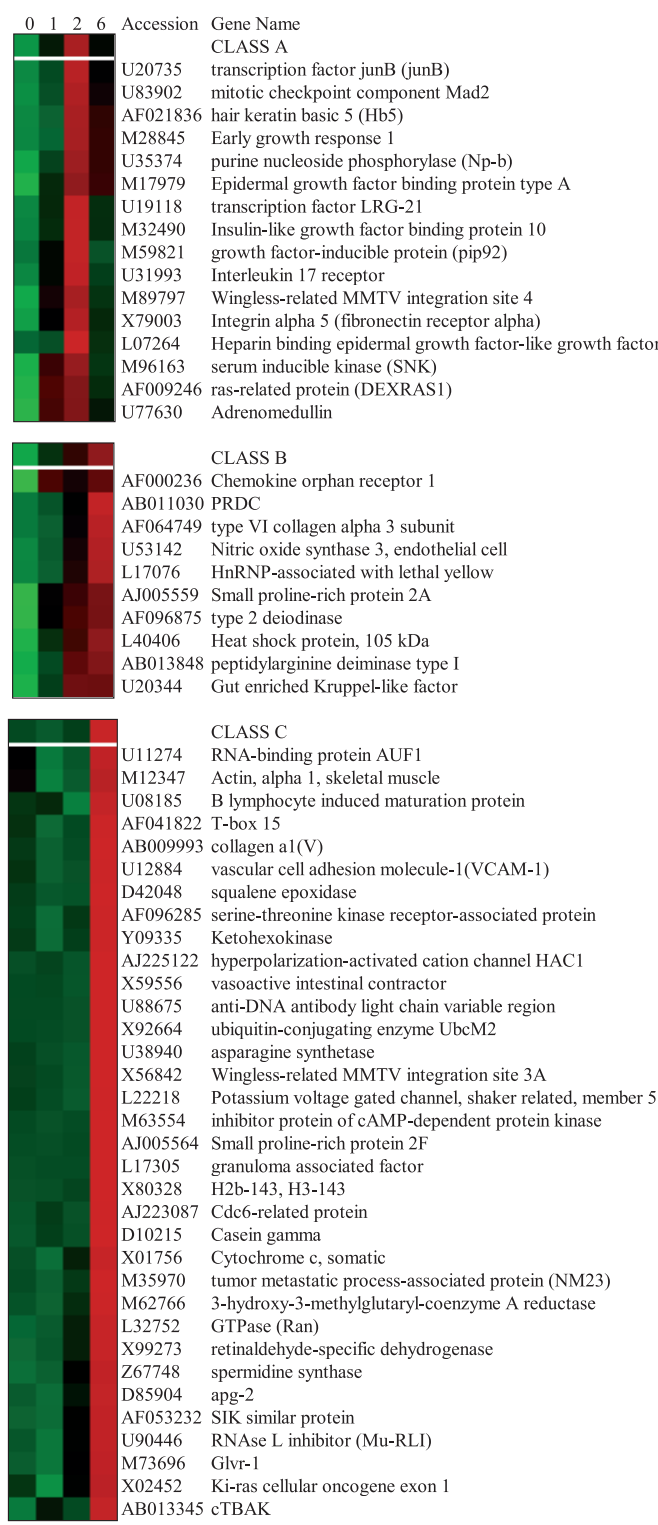

Down Regulated Genes

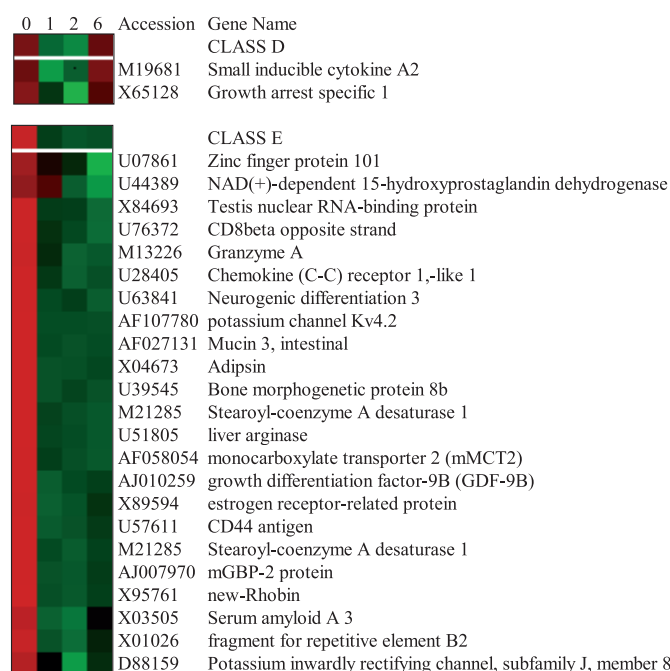

CLASS F

$\begin{array}{lll}\text { U33457 } & \text { Fucosyltransferase } 4 \\ \text { U42467 } & \text { Leptin receptor }\end{array}$

U42467 Leptin receptor

D76440 Necdin

M32032 Selenium binding protein 1

X87096 Brevican

$\begin{array}{ll}\text { X87096 } & \text { Brevican } \\ \text { M88694 } & \text { thioether S-methyltransferase }\end{array}$

$\begin{array}{ll}\text { M88694 } & \text { thioether S-methy } \\ \text { Y17793 } & \text { Dutt1 protein }\end{array}$

$\begin{array}{ll}\text { Y17793 } & \text { Duttl protein } \\ \text { U12791 } & \text { 3-hydroxy-3-methylglutaryl coenzyme A synthase 2 }\end{array}$

AB023957 EIG 180 mRNA for ethanol induced gene product

U95826 cyclin G2

U92068 RecA-like protein (mREC2)

U43541 Laminin, beta 2

U96810 Supt4h2

Y16258 Basigin

Y16258 Basigin

X15643 Adrenergic receptor, beta 2

U73478 Acidic nuclear phosphoprotein 32

AB020886 SSeCKS

M70642 Fibroblast inducible secreted protein

Figure 4 List of clustered genes. The gene names and GenBank accession numbers in each cluster are indicated. Only the genes with annotations are indicated with their gene names. Changes in expression levels are also indicated by color based on normalized values (green indicates low and red indicates high values in normalized values) with time points (in hours) indicated above.

and that $\operatorname{ER} \beta$ cannot compensate for $\mathrm{ER} \alpha$ function. Although ER $\beta$, another weakly expressed $\mathrm{ER}$ in the uterus, is another candidate for E2-dependent changes in gene expression, it was revealed that the contribution of $\operatorname{ER} \beta$ in transcriptional regulation is very small, if it occurs at all.

\section{Discussion}

In this study, we examined temporal gene expression changes at early stages using the DNA microarray technique. Clustering analysis of estrogen-affected genes indicated that some functionally related genes show similar temporal 

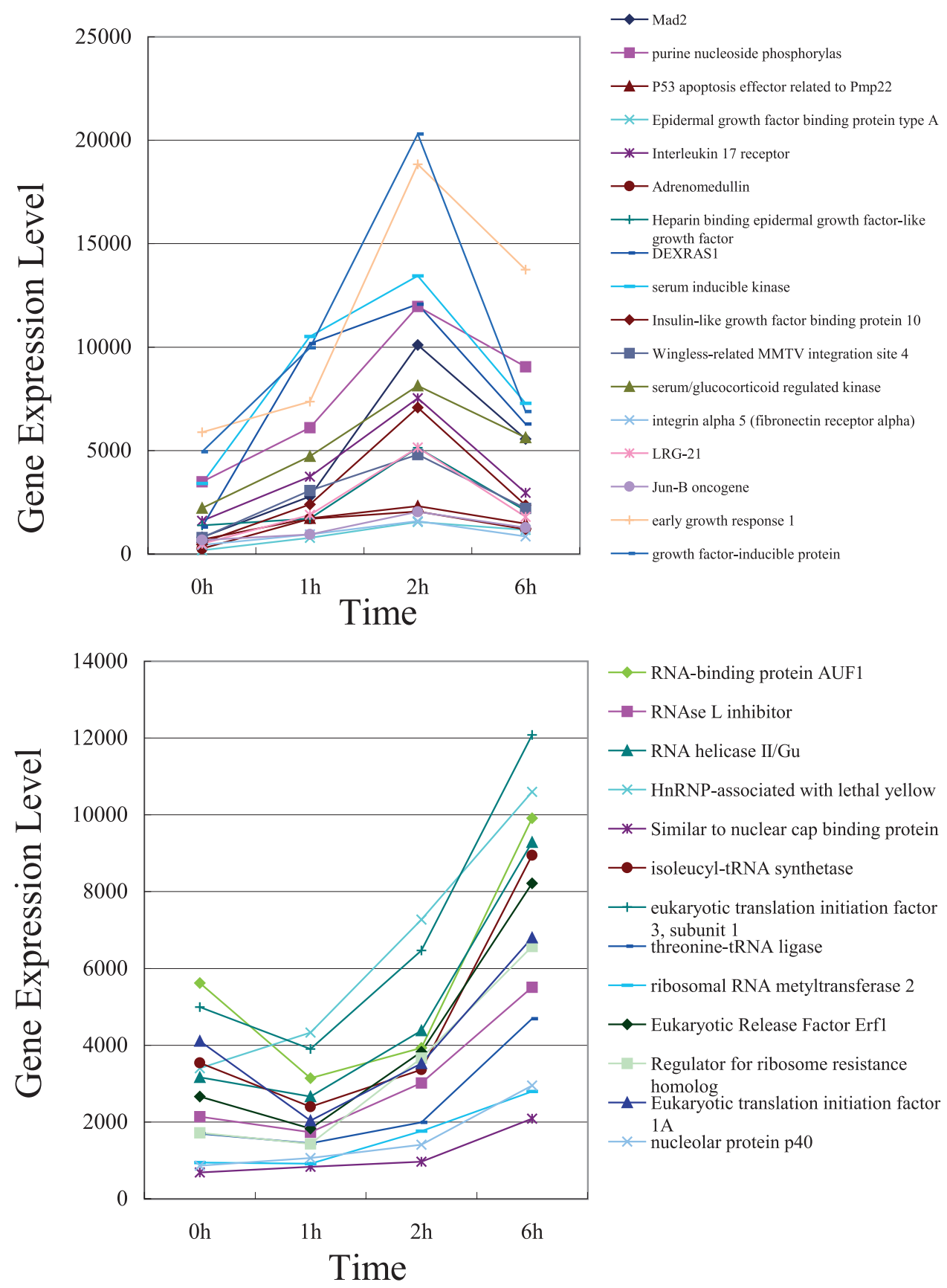

Figure 5 Temporal changes in the expression levels of genes categorized in cluster A (upper panel) and genes related to protein and RNA synthesis (lower panel). X-axis indicates time $(\mathrm{h})$ and $\mathrm{Y}$-axis indicates gene expression levels (average differences) evaluated from DNA microarrays. Genes that were induced more than threefold were selected and plotted.

changes with each other. For example, genes related to signal transduction were mainly found in cluster A, whereas only a few signal transduction genes were categorized in cluster F. Genes related to biosynthesis were mainly found in clusters B and $\mathrm{C}$.

For the clustering analysis, we used six $(3 \times 2)$ node numbers. This node number was optimal for 

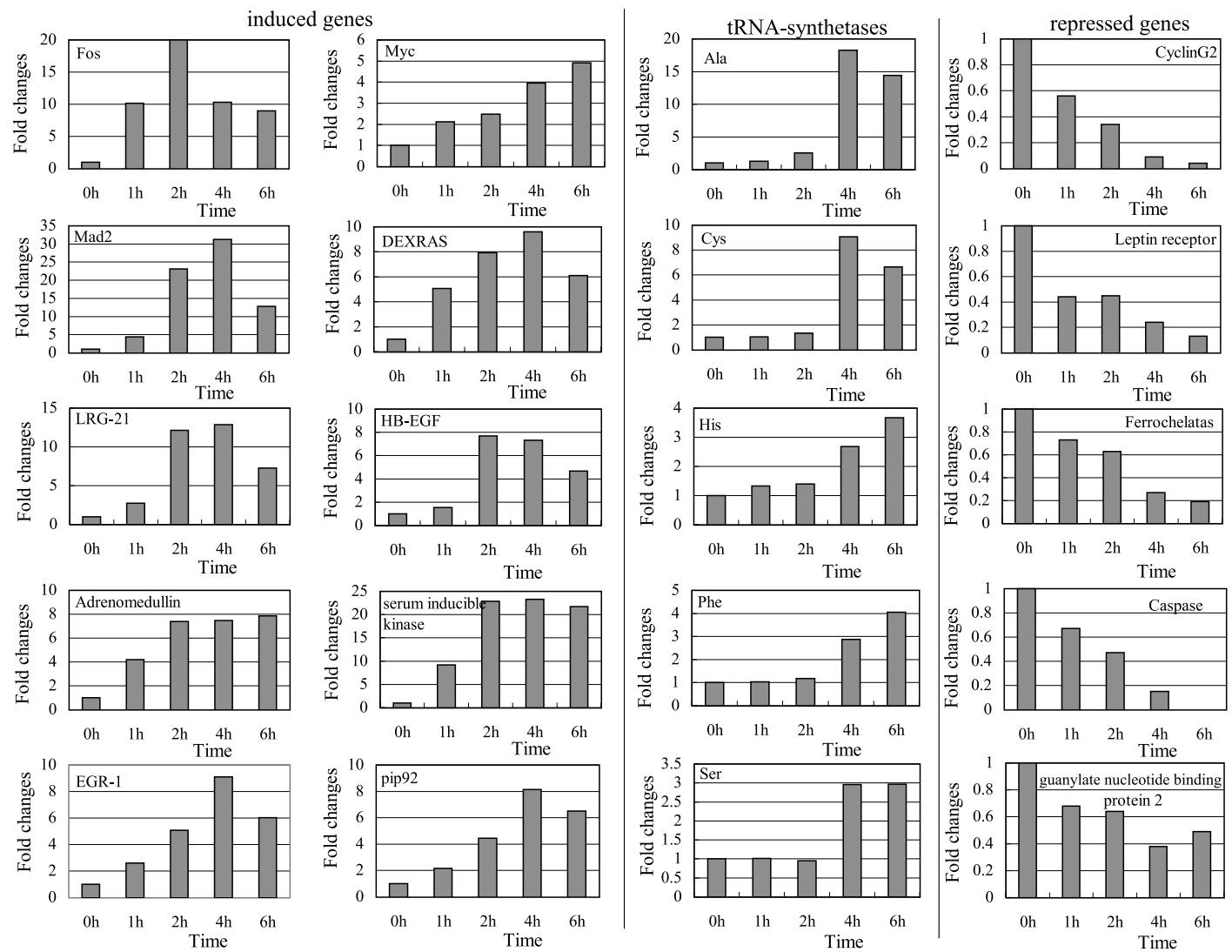

Figure 6 Confirmation of the temporal changes of gene expression levels by quantitative real-time PCR. The fold changes were evaluated by quantitative real-time PCR based on the gene expression levels at $0 \mathrm{~h}$. Representative fold change at each time point is indicated. Names of the examined genes are labeled in each panel.

the clustering of the type of gene expression obtained in this study because it gave independent clustering patterns. As an increment of the node number did not produce any new patterns, it can be concluded that these clusters are representative of the temporal changes in gene expression after estrogen administration.

The fact that the expression pattern of the c-fos (Weisz \& Bresciani 1988) and c-jun (Weisz et al. 1990) gene, a typical immediate-early gene, showed a very similar pattern to that of other genes clustered in A (Fig. 6 and data not shown) confirms that these genes also belong to the immediate-early group of genes, although they were maximally induced $1-2 \mathrm{~h}$ after estrogen administration. The transcription factors and signal transduction genesclustered in A may play an important role in the gene activation or repression of late genes.
In the immediate-early gene cluster, several genes that are known to be induced by growth factors or serum were identified. For example, early growth response gene (egr-1, M28845) (JanssenTimmen et al. 1989), serum inducible kinase gene (M96163) (Simmons et al. 1992), growth factorinducible protein gene (pip92, M59821) (Charles et al. 1990) and serum/glucocorticoid regulated kinase gene (AW046181) (Webster et al. 1993) are known to be activated by serum induction. Among these immediate-early genes, the serum response element is known to be important for the induction of c-fos (Duan et al. 2001), egr-1 (McMahon \& Monroe 1995, de Jager et al. 2001) and pip92 (Chung et al. 1998) but no ERE has been reported in the promoter sequences of these genes. Although a more detailed analysis will be necessary, common mechanisms between serum induction and estrogen 


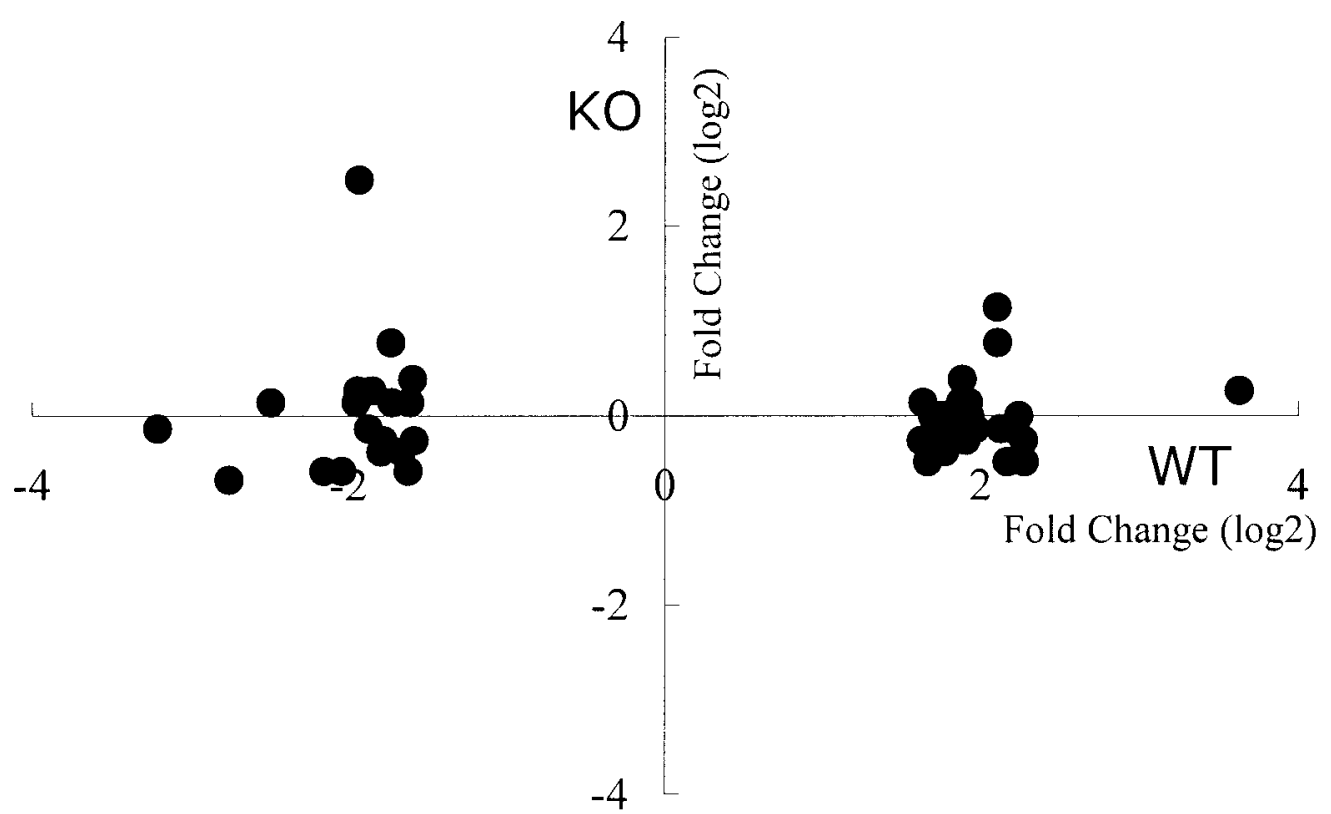

Figure 7 Comparison of the effect of estrogen on gene expression in wild-type (WT) and ERKO (KO) mice. The genes induced or repressed more than threefold at $6 \mathrm{~h}$ were selected from the 182 filtered genes and their fold changes in ERKO mice were calculated based on the ratios of average differences between E2-treated mice and control. The fold changes (log2) in the wild-type are indicated by the X-axis and those in ERKO are indicated by the Y-axis.

may be important for the activation of the immediate-early genes. In this context, nonclassical transcription activation via $\mathrm{Spl}$ or Apl may also play an important role in the gene activation.

Clustering analysis also revealed that large numbers of genes were temporally repressed by E2. Some of the repressed genes indicate characteristic features of the estrogen effect. For example, we found that cyclin G2 was repressed. As this gene is known to arrest cell cycle by interacting with protein phosphatase 2A (Bennin et al. 2002), down-regulation of cyclin G2 may indicate the progression of the cell cycle. We also identified caspase-12 as a temporally repressed gene. This gene product evokes apoptosis by stress in the endoplasmic reticulum (Nakagawa et al. 2000). As suggested by the induced genes, many genes related to translation and transportation were activated by estrogen, which may cause stress in the endoplasmic reticulum. Thus repression of the gene related to endoplasmic reticulum stress-induced apoptosis may be responsible for rapid protein synthesis and secretion. Down-regulation of leptin receptor gene is consistent with other gene expression changes which direct sterol synthesis (Watanabe et al. 2002), as it is known that leptin represses the gene expression related to fatty acid and cholesterol synthesis (Liang \& Tall 2001).

Our analysis could not cluster all the genes activated by estrogen probably because the time window was rather narrow, the threshold of our analysis was too high and/or some genes were poorly represented on the array. For example, complement C3 (Sundstrom et al. 1989), epidermal growth factor (EGF) (DiAugustine et al. 1988), EGF receptors (Gardner et al. 1989), muc-1 (Surveyor et al. 1995), lactoferrin (Teng et al. 1989) and the progesterone receptor (Manni et al. 1981) could not be selected because the expression levels of these genes did not change during the 6 -h period after E2 administration. These genes are known to be activated at $12 \mathrm{~h}$ or one or two days after E2 administration. Ornithine decarboxylase was not selected by the clustering analysis because of the rather strict criteria for gene selection. It was activated nearly threefold at $6 \mathrm{~h}$ (data not shown). Estrogen-responsive finger protein is also known to be activated by estrogen within $10 \mathrm{~h}$ (Inoue et al. 
1993), but this gene was not arrayed on the DNA microarray. Some genes, such as uteroglobin, hsp27 and calbindin (D9k), were not detected by the microarray probably because of restricted expression of the genes.

In this study, early events preceding the uterotropic effect could be identified at the transcription level, resulting in the identification of novel gene clusters whose members are most likely responsible for the triggering of uterotropic effects. As several transcription factors and genes related to growth signaling were clustered as immediate-early genes, these genes may play an important role in subsequent changes in gene expression. Functional analysis of these clustered genes and analysis of their regulation will provide new insights into the estrogen effect in vivo.

\section{Acknowledgements}

This work was supported in part by a research grant from Core Research for Evolutional Science of Japan Science and Technology Cooperation, Grant-in-Aid for Scientific Research of Japan Society for the Promotion of Science, NEDO and the Ministry of Environment.

\section{References}

Anzick SL, Kononen J, Walker RL, Azorsa DO, Tanner MM, Guan XY, Sauter G, Kallioniemi OP, Trent JM \& Meltzer PS 1997 AIB1, a steroid receptor coactivator amplified in breast and ovarian cancer. Science 277 965-968.

Bennin DA, Don AS, Brake T, McKenzie JL, Rosenbaum H, Ortiz L, DePaoli-Roach AA \& Horne MC 2002 Cyclin G2 associates with protein phosphatase $2 \mathrm{~A}$ catalytic and regulatory B' subunits in active complexes and induces nuclear aberrations and a G1/S phase cell cycle arrest. Fournal of Biological Chemistry 277 27449-27467.

Chakravarti D, LaMorte VJ, Nelson MC, Nakajima T, Schulman IG, Juguilon H, Montminy M \& Evans RM 1996 Role of CBP/P300 in nuclear receptor signalling. Nature 383 99-103.

Charles CH, Simske JS, O'Brien TP \& Lau LF 1990 Pip92: a short-lived, growth factor-inducible protein in BALB/c 3T3 and PC12 cells. Molecular Cell Biology 10 6769-6774.

Chung KC, Gomes I, Wang D, Lau LF \& Rosner MR 1998 Raf and fibroblast growth factor phosphorylate Elkl and activate the serum response element of the immediate early gene pip92 by mitogen-activated protein kinase-independent as well as -dependent signaling pathways. Molecular Cell Biology 18 2272-2281.

Couse JF \& Korach KS 1999 Estrogen receptor null mice: what have we learned and where will they lead us? Endocrine Reviewes 20 358-417.

DiAugustine RP, Petrusz P, Bell GI, Brown CF, Korach KS, McLachlan JA \& Teng CT 1988 Influence of estrogens on mouse uterine epidermal growth factor precursor protein and messenger ribonucleic acid. Endocrinology 122 2355-2363.

Duan R, Xie W, Burghardt RC \& Safe S 2001 Estrogen receptor-mediated activation of the serum response element in MCF-7 cells through MAPK-dependent phosphorylation of Elk-1. Fournal of Biological Chemistry 276 11590-11598.

Feng X, Jiang Y, Meltzer P \& Yen PM 2000 Thyroid hormone regulation of hepatic genes in vivo detected by complementary DNA microarray. Molecular Endocrinology 14 947-955.

Gardner RM, Verner G, Kirkland JL \& Stancel GM 1989 Regulation of uterine epidermal growth factor (EGF) receptors by estrogen in the mature rat and during the estrous cycle. Fournal of Steroid Biochemistry 32 339-343.

Green S, Walter P, Kumar V, Krust A, Bornert JM, Argos P \& Chambon P 1986 Human oestrogen receptor cDNA: sequence, expression and homology to v-erb-A. Nature 320 134-139.

Huet-Hudson YM, Chakraborty C, De SK, Suzuki Y, Andrews GK \& Dey SK 1990 Estrogen regulates the synthesis of epidermal growth factor in mouse uterine epithelial cells. Molecular Endocrinology 4 510-523.

Inoue $\mathrm{S}$, Orimo A, Hosoi $\mathrm{T}$, Kondo $\mathrm{S}$, Toyoshima $\mathrm{H}$, Kondo $\mathrm{T}$, Ikegami A, Ouchi Y, Orimo H \& Muramatsu M 1993 Genomic binding-site cloning reveals an estrogen-responsive gene that encodes a RING finger protein. PNAS 90 11117-11121.

Iyer VR, Eisen MB, Ross DT, Schuler G, Moore T, Lee JC, Trent JM, Staudt LM, Hudson J Jr, Boguski MS, Lashkari D, Shalon D, Botstein D \& Brown PO 1999 The transcriptional program in the response of human fibroblasts to serum. Science 283 83-87.

de Jager T, Pelzer T, Muller-Botz S, Imam A, Muck J \& Neyses L 2001 Mechanisms of estrogen receptor action in the myocardium. Rapid gene activation via the ERK1/2 pathway and serum response elements. Fournal of Biological Chemistry 276 27873-27880.

Janssen-Timmen U, Lemaire P, Mattei MG, Revelant O \& Charnay P 1989 Structure, chromosome mapping and regulation of the mouse zinc-finger gene Krox-24; evidence for a common regulatory pathway for immediate-early serum-response genes. Gene 80 325-336.

Kuiper GG, Enmark E, Pelto-Huikko M, Nilsson S \& Gustafsson JA 1996 Cloning of a novel receptor expressed in rat prostate and ovary. PNAS 93 5925-5930.

Liang CP \& Tall AR 2001 Transcriptional profiling reveals global defects in energy metabolism, lipoprotein, and bile acid synthesis and transport with reversal by leptin treatment in ob/ob mouse liver. Fournal of Biological Chemistry 276 49066-49076.

Liu SC, Sanfilippo B, Perroteau I, Derynck R, Salomon DS \& Kidwell WR 1987 Expression of transforming growth factor alpha (TGF alpha) in differentiated rat mammary tumors: estrogen induction of TGF alpha production. Molecular Endocrinology 1 683-692.

Lockhart DJ, Dong H, Byrne MC, Follettie MT, Gallo MV, Chee MS, Mittmann M, Wang C, Kobayashi M, Horton H \& Brown EL 1996 Expression monitoring by hybridization to high-density oligonucleotide arrays. Nature Biotechnology 14 1675-1680.

Lubahn DB, Moyer JS, Golding TS, Couse JF, Korach KS \& Smithies O 1993 Alteration of reproductive function but not prenatal sexual development after insertional disruption of the mouse estrogen receptor gene. PNAS $9011162-11166$.

McMahon SB \& Monroe JG 1995 A ternary complex factor-dependent mechanism mediates induction of egr-1 through selective serum response elements following antigen receptor cross-linking in B lymphocytes. Molecular Cell Biology $\mathbf{1 5}$ 1086-1093.

Manni A, Baker R, Arafah BM \& Pearson OH 1981 Uterine oestrogen and progesterone receptors in the ovariectomized rat. fournal of Endocrinology 91 281-287. 
Marton MJ, DeRisi JL, Bennett HA, Iyer VR, Meyer MR, Roberts CJ, Stoughton R, Burchard J, Slade D, Dai H, Bassett DE Jr, Hartwell LH, Brown PO \& Friend SH 1998 Drug target validation and identification of secondary drug target effects using DNA microarrays. Nature Medicine 4 1293-1301.

Murphy LJ, Murphy LC \& Friesen HG 1987 Estrogen induces insulin-like growth factor-I expression in the rat uterus. Molecular Endocrinology 1 445-450.

Nakagawa T, Zhu H, Morishima N, Li E, Xu J, Yankner BA \& Yuan J 2000 Caspase-12 mediates endoplasmic-reticulum-specific apoptosis and cytotoxicity by amyloid-beta. Nature 403 98-103.

Onate SA, Tsai SY, Tsai MJ \& O'Malley BW 1995 Sequence and characterization of a coactivator for the steroid hormone receptor superfamily. Science 270 1354-1357.

Pentecost BT \& Teng CT 1987 Lactotransferrin is the major estrogen inducible protein of mouse uterine secretions. Fournal of Biological Chemistry 262 10134-10139.

Simmons DL, Neel BG, Stevens R, Evett G \& Erikson RL 1992 Identification of an early-growth-response gene encoding a novel putative protein kinase. Molecular Cell Biology 12 $4164-4169$.

Sundstrom SA, Komm BS, Ponce-de-Leon H, Yi Z, Teuscher C \& Lyttle CR 1989 Estrogen regulation of tissue-specific expression of complement C3. Fournal of Biological Chemistry 264 16941-16947.

Surveyor GA, Gendler SJ, Pemberton L, Das SK, Chakraborty I, Julian J, Pimental RA, Wegner CC, Dey SK \& Carson DD 1995 Expression and steroid hormonal control of Muc-1 in the mouse uterus. Endocrinology 136 3639-3647.
Tamayo P, Slonim D, Mesirov J, Zhu Q, Kitareewan S, Dmitrovsky E, Lander ES \& Golub TR 1999 Interpreting patterns of gene expression with self-organizing maps: methods and application to hematopoietic differentiation. PNAS 96 2907-2912.

Teng CT, Pentecost BT, Chen YH, Newbold RR, Eddy EM \& McLachlan JA 1989 Lactotransferrin gene expression in the mouse uterus and mammary gland. Endocrinology 124 992-999.

Wang XN, Das SK, Damm D, Klagsbrun M, Abraham JA \& Dey SK 1994 Differential regulation of heparin-binding epidermal growth factor-like growth factor in the adult ovariectomized mouse uterus by progesterone and estrogen. Endocrinology 135 $1264-1271$

Watanabe H, Suzuki A, Mizutani T, Khono S, Lubahn DB, Handa H \& Iguchi T 2002 Genome-wide analysis of changes in early gene expression induced by oestrogen. Genes Cells 7 497-507.

Webster MK, Goya L, Ge Y, Maiyar AC \& Firestone GL 1993 Characterization of sgk, a novel member of the serine/threonine protein kinase gene family which is transcriptionally induced by glucocorticoids and serum. Molecular Cell Biology 13 2031-2040.

Weisz A \& Bresciani F 1988 Estrogen induces expression of c-fos and c-myc protooncogenes in rat uterus. Molecular Endocrinology 2 816-824.

Weisz A, Cicatiello L, Persico E, Scalona M \& Bresciani F 1990 Estrogen stimulates transcription of c-jun protooncogene. Molecular Endocrinology 4 1041-1050.

Received 4 October 2002

Accepted 31 January 2003 